\title{
Kamu Sektörü Dinamikleri Çerçevesinde İletişim Taktiği Olarak Stratejik Muğlaklığın Değerlendirilmesi
}

\author{
Özlem ARACI ${ }^{*}$
}

Kamu Sektörü Dinamikleri Çerçevesinde İletişim Taktiği Olarak Stratejik Muğlaklığın Değerlendirilmesi

Özet

Stratejik muğlaklık, farklı görüşlerin ve yorumların ortaya çıkmasını tetikleyen muğlak mesajları içeren bir iletişim taktiği olarak kabul edilir. Bu çalışmanın amacı kamu sektörünün dinamikleri içinde iletişim taktiği olarak stratejik muğlaklığın değerlendirilmesidir. Kamu sektöründe faaliyet gösteren kurumların paydaş çeşitliliğinin özel sektörde faaliyet gösteren kurumlara görece daha fazla olması sonucu, birbirleri ile çelişen paydaş çıkarlarının dengelenme gerekliliği stratejik muğlaklığın bir iletişim taktiği olarak kullanımı ile karşılanabilir. Öte yandan, kamu sektörünün tarafıızık, eşitlik, hesap verebilirlik, şeffaflık gibi kendine özgü diğer dinamikleri ise iletişim taktiği olarak stratejik muğlaklı̆ın sorgulanmasına neden olmaktadır. Çalışma, stratejik muğlaklığı bu ikilem arasında değerlendirerek literatüre katkı sağlamaktadır. Konunun ulusal literatürde, özellikle de kamu sektörü ile ilişkilendirilerek incelenmemiş olması gelecek çalışmalar için yeni araştırma sorularının ortaya çıkmasını tetiklemektedir.

Anahtar Kelimeler: Stratejik Muğlaklık, Kamu Sektörü, Paydaşlar ile iletişim
Evaluation of Strategic Ambiguity as a Communication Tactic within the Dynamics of the Public Sector

Abstract

Strategic ambiguity is considered as a communication tactic involving ambiguous messages that trigger to emergence of different opinions and interpretations. The purpose of this study is to evaluate strategic ambiguity as a communication tactic within the dynamics of the public sector. As a result of the stakeholder diversity of organizations operating in the public sector is greater than those operating in the private sector, necessity to balance multiple competing interests of stakeholders can be met by the use of strategic ambiguity as a communication tactic. On the other hand, public sector dynamics such as impartiality, equality, accountability, transparency cause strategic ambiguity to be questioned as a communication tactic. This study contributes to the literature by assessing strategic ambiguity among these dilemmas. The fact that it has not been examined in the national literature, especially in relation to public sector, has triggered to emergence of new research questions for future studies.

Key Words: Strategic Ambiguity, Public Sector, Communication with Stakeholders

\section{Giriş}

Organizasyonlar çevreyi etkileyen ve çevreden etkilenen bir yapıya sahiptir. Organizasyonun kararları, uygulamaları bu çevrede varık gösteren paydaşlarını etkiler. Paydaşları da kendilerini etkileyecek olan konular karşısında organizasyonun tutumlarını, kararlarını öğrenmek ister. Öte yandan paydaşlar da organizasyonun kararlarını ve uygulamalarını etkileme potansiyeline sahiptir.

* Özlem ARACl, Dr.Öğr.Üyesi., İstanbul Üniversitesi, Siyaset Bilimi ve Kamu Yönetimi Bölümü, ozlem.araci@istanbul.edu.tr ,ORCID ID orcid.org / 0000-0003-1205-4383 


\section{Özlem ARACl}

Bu durum her iki tarafın birbirleri ile iletişim kurmasını zorunlu kılmaktadır. Iletişim, tarafların davranışlarını etkileme fonksiyonu dışında motivasyon ve ikna etme amacı ile de kullanılan, bilginin değiş tokuş edildiği bir süreçtir (Daft, 2010,s.537).Bu süreç, organizasyon ve paydaşlarına içinde bulunulan koşullara göre gönderici ve alıcı rolleri biçer. Organizasyondan paydaşlarına doğru bir iletişim yönü olabileceği gibi, paydaşlardan organizasyona doğru bir iletişim yönü olabilir.

Illetişimin gerekliliği ve önemi, etkin bir iletişim sağlanması gerekliliğini de beraberinde getirmektedir. Göndericinin anlatmak istediği ile alıcının anladığının örtüşmesi önemli bir etkin iletişim ölçütüdür. Konu ile ilgili çalışmalarda iletişim sürecinde açık ve net mesajların kullanılması gerektiği, aksi halde karşılıkı bir anlayış geliştirilemeyeceği etkin iletişim yolu olarak ifade edilmiştir. Ancak daha sonraki çalışmalarda, içinde bulunulan koşullara bağlı olarak, açık ve net mesajlar kullanmak yerine bilinçli bir şekilde muğlak mesajlar kullanmanın da bir iletişim taktiği olabileceği ifade edilmiştir (ör. Eisenberg, 1984; Paul ve Strbiak, 1997). Iletişim sürecinde açık ve net olmak bazen kişisel yaratıcılığı ve girişimciliği kısıtlamak gibi istenmeyen sonuçlar yaratabilir (Leitch ve Davenport,2003). Belirsiz bir içerik anlaşıımaya çalışıırken yaratıcılığı teşvik ederek çok çeşitli yorumların ortaya çıkmasını tetikleyebilir. Contractor ve Ehrlich (1993) organizasyonları açıklamayı amaçlayan birçok kuramda "iletişimin" bir problem olarak değerlendirilmediğini, oysaki organizasyonların başarılı bir şekilde doğması, oluşması sürecinde muğlak iletişim taktiğinin önemli bir role sahip olduğunu ifade etmişlerdir. Özellikle, belirsizliğin ve hızlı değişimlerin hakim olduğu süreçte, paydaşların gözünde ne tür stratejilerin uygun olduğunu teşhis etmede, muğlak iletişim daha fazla yarar sağlayabilir(Eisenberg,1984).

Bu kavram literatürde "stratejik muğlaklık (strategic ambiguity)" olarak yer bulmuştur. Stratejik muğlaklık, iletişim sürecinde açık ve net olmanın önemini göz ardı etmeden, içinde bulunulan koşullara göre farklı anlamların çıkarılabileceği muğlak mesajları içeren bir iletişim taktiği olarak kabul edilebilir (Eisenberg, 1984, s.229). Stratejik muğlaklık, iletişim sürecinde açık ve net olmanın faydaları kadar, farklı görüşlerin ortaya çıkmasının yaratacağı faydaları da göz önünde bulundurur. Stratejik muğlaklık, Davenport ve Leitch (2005, s.1604) tarafından, paydaş yorumlarını çeşitlendirmek ve olası tepkilerini belirlemek amacı ile stratejik iletişimde muğlaklığın bilinçli şekilde kullanıması şeklinde tanımlanmıştır. Bu doğrultuda stratejik muğlaklık sadece görüş çeşitliliğini artırarak değil, nihai karar ya da faaliyet öncesinde paydaşların ne tür tepkiler geliştireceğini göstererek organizasyonun gerekli önlemleri alması, düzeltmeleri yapması için alan yaratmış olur. Paydaşlar oluşturdukları çeşitli görüşler ile, geliştirdikleri tepkiler ile sürece dahil olurlar. Muğlaklığın stratejik olarak kullanılması, paydaşlara yetki devri sağlayarak gücün, kurum ve paydaşlar arasında paylaşılmasını mümkün kılan bir fayda yaratmaktadır (Davenport ve Leitch, 2005, s.1604).

Bu çalışmanın amacı kamu sektörünün dinamikleri içinde iletişim taktiği olarak stratejik muğlaklığın değerlendirilmesidir. Kamu yönetiminin etki alanının genişliği çok çeşitli paydaşların dahil olduğu bu alanda etkin iletişimi gerekli kılmaktadır. Öyle ki, iletişim hatalarının bir ülkenin güvenilirliğini, prestijini kaybetmesine neden olma potansiyeli iletişim meselesinin stratejik önemini artırmaktadır (Goodall, Trethewey ve McDonald, 2006). Kamu sektöründe faaliyet gösteren kurumla- 
rın, birbirleri ile çelişen paydaş çıkarlarını dengeleme gerekliliği stratejik muğlaklığın bir iletişim taktiği olarak kullanımı ile karşılanabilir. Öte yandan, kamu hizmeti bilinci, tarafsızlık, eşitlik, hesap verebilirlik, şeffaflık gibi kamu sektörünün kendine özgü dinamikleri iletişim taktiği olarak stratejik muğlaklığın kullanımını sorgulatmaktadır.

Çalışma, stratejik muğlaklığı bu ikilem arasında değerlendirerek literatüre katkı sağlayacaktır. Konunun ulusal literatürde, özellikle de kamu sektörü ile ilişkilendirilerek incelenmemiş olması gelecek çalışmalar için yeni araştırma sorularının ortaya çıkmasını tetikleyecektir.

Çalışmanın içeriğinde öncelikli olarak stratejik muğlaklığın literatürdeki yeri yapılan çalışmalara dayalı olarak incelenecektir. İletişim taktiği olarak stratejik muğlaklık kamu sektörü dinamikleri içinde değerlendirilecektir. Stratejik muğlaklığın etik olup olmadığı, hangi koşullarda etik olacağı hususundaki farklı görüşlere yer verilerek değerlendirilmesi yapılacaktır. Sonuç ve öneriler kısmı, stratejik muğlaklık ile ilgili ikilemlere dikkat çekerek, gelecek çalışma önerilerini içerecektir.

\section{Illetişim Taktiği Olarak Stratejik Muğlaklık}

Stratejik muğlaklık kavramı Eisenberg (1984) öncesinde, birebir "stratejik muğlaklık" olarak ifade edilmese de Aristotle söylemlerinde, kelimelerin tek bir anlamının olmadığına, anlamın insanlarda gizli olduğuna yer vermiştir (Tarbet, 2010, s.4). 1980'li yılların öncesinde iletişimde muğlaklık; Zimbardo (1960) tarafından incelenmiş ve konu ile ilgili pozitif tutuma sahip bireylerin muğlak mesajları daha tatminkâr buldukları ifade edilmiştir. Samovar (1962) muğlak bir paragrafın okunması sonucunda ortaya çıkan yorumların (ortalama 15,5); açık ve net bir paragrafın okunması sonucunda ortaya çıkan yorumlardan (ortalama 6,6 ) daha fazla olduğunu ortaya koymuştur. Williams ve Goss (1975) organizasyonların, paydaşlar ile anlaşma sağlanan konular üzerinde açık iletişimi tercih etmeleri gerektiğini, çıkar çatışmalarının olduğu konular üzerinde muğlak mesajları tercih ederek anlaşmazlık kaynaklarının artmasını engelleyeceklerini savunmuşlardır.

Eisenberg (1984,s.229) tarafından muğlaklık (ambiguity), anlamdaki görecelilik olarak tanımlanırken, Weick (1995,s.91-92) muğlaklığı, birbirinden farklı yorumların eşanlı oluştuğu bir durum olarak tanımlamıştır. Muğlak bir mesajın özellikleri; soyut bir dil kullanımı, spesifik detayların eksikliği, belirli bir hareket tarzını desteklememesi, mesajın belirsiz olarak algılanması şeklinde sıralanabilir (Putnam, 1981,s.9).

Stratejik muğlaklığın tanımlarında ise stratejik muğlaklığın fonksiyonlarına odaklanıldığı görülmektedir. Eisenberg (1984,s.229) stratejik muğlaklığı "birbiri ile çelişen amaçları tatmin etme yolu" olarak tanımlayarak stratejik muğlaklığın, paydaşları tatmin etme fonksiyonunu vurgulamıştır. Kline, Simunich ve Weber (2008,s.786) stratejik muğlaklığı, bilginin paydaşların endişeleri dikkate alınarak yönetilmesi şeklinde tanımlayarak stratejik muğlaklığın bilgi yönetimi fonksiyonuna dikkat çekmiştir. Stratejik muğlaklığın vurgulanan diğer fonksiyonu ise kriz dönemlerinde kurum itibarını korumayı sağlamasıdır. Özellikle krizin başlangıç zamanlarında potansiyel çıkar çatışmalarının daha yoğun olduğu dönemde, muğlak mesaj kullanımının daha uygun bulunduğu ifade edilmiştir (Kline vd., 2008). Organizasyon düzeyindeki fonksiyonlarının yanı sıra, stratejik muğlaklık bireysel düzey- 


\section{Özlem ARACI}

de de yaratııılığı ortaya çıkarmak için alan yaratmaktadır (Leitch ve Davenport, 2003, s.130). Muğlak mesajlar anlaşılmaya çalışılırken farklı yorumlar ve görüşler ortaya çıkmaktadır.

Stratejik olarak muğlak mesajlar "tam olarak bilgilendirilmiş şekilde karar vermek" için gerekli standartların tümünü veya birkaçını zedeleyebilir (Millner, 2011, s.27). Ulmer, Sellnow ve Seeger (2011, s.195) belirtilen bu standartları; 1- Paydaşlar fiziki ve mental zorlama altında değildir, 2Seçim mevcut olan tüm bilgiye dayalı olarak yapılır, 3-Makul tüm alternatifler tartışılır, 4-Kısa dönemli ve uzun dönemli sonuçlar tartışılır, 5-Göndericiler ve alıcılar kararlarında etkili olan kişisel gerekçeleri konusunda açıktır şeklinde vurgulamıştır. Muğlaklığın stratejik olarak kullanımında bu standartlar zedelenir. Örneğin, organizasyon, makul tüm alternatiflerin kısa veya uzun dönemli sonuçlarını tartışmayarak mesajını açık ve net olmaktan uzaklaştırmış olur.

Organizasyonlar, paydaşların taleplerini karşılayarak, çıkarlarını koruyarak amaçlarını gerçekleştirmeye çalışırlar. İletişim taktiği olarak stratejik muğlaklığın uygulanması, tek bir amacı maksimize etmek için değil, birbirleri ile çelişen çıkarları olan farklı paydaşları tatmin etme çabası olarak değerlendirilmelidir. Dolayısıyla, muğlaklığın, stratejik muğlaklık olarak değerlendirilmesi iletişim taktiği olarak kasten, bilerek kullanılmasını gerektirir (Leitch ve Davenport, 2007; Eisenberg, 1984). Muğlaklığın kasten, bilerek kullanımasının amacı da, istenen davranışların oluşmasını sağlamak amacıyla paydaşlar üzerinde etki yaratılmaya çalışılmasıdır (Davenport ve Leitch, 2005, s.1619). Smith, Atkin ve Roznowski (2006) stratejik muğlaklığın manipülatif yönü üzerinde durmuştur. Alkol üreticilerinin reklamlarında bilinçli olarak kullandıkları muğlaklık dolayısıyla toplumda sosyal sorumlu olarak algılanmaları sağlanmış ve birçok paydaşın ihtiyaçlarına ve isteklerine duyarlı çeşitli yorumların ortaya çıkması tetiklenmiştir(Smith vd.,2006).

Organizasyonların paydaşlarının farklı çıkarlarını eş anlı ve eşit şekilde yönetmesi ve birbirleri ile çelişen çıkarların koordinasyonunu sağlamaları gerekir (Donaldson ve Preston, 1995). Bu doğrultuda stratejik muğlaklık organizasyonların içinde bulunulan koşullara bağlı olarak paydaş çıkarları arasında denge kurmasına, bir paydaşın çıkarını diğerinden üstün tutmadığını göstermesine olanak sağlar. Bu durum, birbirleri ile çelişen çıkarları olan farklı grupların birlikteliğini mümkün kılar (Leitch ve Davenport, 2007,s.44). Anlamdaki göreceliliği besleyecek şekilde müphem mesajların kullanılması, paydaşların konu ile ilgili görüşlerini, yorumlarını çeşitlendirerek, paydaşların organizasyon karar ve süreçlerine katılımı desteklenmiş olur. Paydaş çıkarlarının dengelenmesi, paydaş katıımcıIığı için alan yaratılması organizasyona duyulan güven seviyesini de olumlu yönde etkileyecektir. Organizasyonların iletişim taktiği olarak muğlaklı̆̆ yönetebilmeleri, güvenilirlik ve meşruluk kazanacak bir kimlik oluşturmaları için de gerekli görülmektedir (Cheney ve Christensen, 2001)

Stratejik muğlaklık katılımcılığın sağlanması, organizasyonun algıyı yönetmesi için alan yaratması, faaliyet gerçekleşmeden önce olası tepkilerin öngörülmesi gibi faydalar yaratsa da, bu faydaların ortaya çıkması için paydaşların muğlak olan durumu pozitif olarak değerlendirme eğilimi, paydaşların kaynakları ve yetenekleri, muğlaklık ile mücadele motivasyonu, organizasyona karşı duydukları güven önemli öncüllerdir (Leitch ve Davenport, 2003). Williams ve Goss (1975) muğlak 
iletişimi tercih eden gönderici ile açık iletişimi tercih eden gönderici karşılaştırmasında yetkinlik açısından fark olmamasına rağmen, muğlak iletişimi tercih eden kaynağın daha güvenilir bulunduğu sonucuna erişmiştir. Markham (1996) ise örgüt içi iletişimde stratejik muğlaklığın çalışanlar üzerindeki etkisini incelenmiştir. Bu çalışmada yöneticiler stratejik muğlaklığı yaratıclığı teşvik etmek için kullanmış olsalar da, bu tutum çalışanlar tarafından "çelişkili ve kısıtlayııı" olarak algılanmıştır.

\section{1. İletişim Taktiği Olarak Stratejik Muğlaklığın Fonksiyonları ve Riskleri}

Stratejik muğlaklığın 4 temel fonksiyonu bulunmaktadır (Eisenberg,1984); "farklı görüşleri içeren ortak bir taban oluşturması", "organizasyon düzeyinde değişimi kolaylaştırması", "var olan kaynak özelliklerini güçlendirmesi ve ayrıcalıklı pozisyonları koruması", "gelecek alternatifleri korumasıdır". Leitch ve Davenport $(2003, s .133)$ "organizasyona zaman ve olayları değerlendirmek için bir alan kazandırma" olmak üzere beşinci bir fonksiyon eklenmiştir. Bu fonksiyon istenen değişim karşısında tüm prosedürlerin tamamlanmasını beklemek yerine stratejik muğlaklığın değişimi hızlandıracağına işaret etmektedir (Leitch ve Davenport, 2003).

Farklı görüşleri içeren ortak bir taban oluşturması: Farklı görüşlerin ortaya çıkmasının sağlanması, soyutluğun beslenmesi konu ile ilgili yorumlarda bir çeşitlilik yaratır (Eisenberg ve Goodall, 1997). Çevresel değişimlere uyum sağlamanın organizasyonun yaşamı üzerindeki etkisi daha esnek ve yaratıc olmayı gerektirmektedir. Stratejik olarak kullanılan muğlak mesajlar da hem fikir olma izlenimi yaratırken eş anlı olarak farklı yorumların, görüşlerin ortaya çıkmasını (Eisenberg, 1984) tetikleyerek organizasyonu esnek ve yaratıcı olma konusunda güçlendirebilir. Organizasyonlar misyonlarını muğlak bir şekilde ifade edebilirler, böylelikle çok çeşitli yorumlamaların ortaya çıkmasını tetiklerken, öte yandan açık ve net olmadığı için insanlara uyum içinde olunduğu izlenimi yaratır (Contractor ve Ehrlich, 1993). Örneğin, kamu sektöründeki paydaşların çeşitliliği dikkate alındığında her birinin ayrı endişesi ve çıkarı var. Kurum bir grubu diğerinden üstün tutmayacak şekilde mesajlar ileterek her bir paydaşın o mesajdan kendi lehine çıkarımlarda bulunmasını sağlar.

Organizasyon düzeyinde değişimi kolaylaştırması: Stratejik muğlaklık sonucu oluşan farklı görüşler, yorumlar organizasyonlara değişim için serbestlik sağlar (Eisenberg, 1984). Organizasyon, muğlaklığın yarattığı bu farklı görüş açılarını organizasyonun hedeflerine ve stratejilerine yaklaştırabilir ya da bu çeşitlilik sayesinde hedeflerin, stratejilerin zamanla yanlış olduğunu fark edip değiştirebilir (Eisenberg, 1984). Değişim sürecinde paydaşların farklı görüşleri ve yorumları ile sürecin bir parçası olarak fayda sağlayacaklarını düşünmeleri de stratejik muğlaklığın etkinliğini olumlu etkileyecektir (Leitch ve Davenport, 2003). Öte yandan, muğlak iletişim altındaki paydaşlar muğlaklığı ortadan kaldırma motivasyonu ile birbirleri ile daha fazla etkileşim halinde olarak değişime destek verebilir (Eisenberg,1984). Denilebilir ki, muğlaklık bir taraftan sürekliliği korurken, diğer taraftan yorumların, görüşlerin zamanla değişmesine olanak sağlar (Eisenberg,1984).

Varolan kaynak özelliklerini güçlendirmesi ve ayrıcalıklı pozisyonları koruması: Stratejik muğlaklığın ayrıcalıklı pozisyonları koruma fonksiyonu özellikle paydaşların organizasyona karşı negatif bir tepki geliştirme durumunda anlamlı olacaktır (Eisenberg,1984). Örneğin, organizasyon 
kriz zamanlarında iletişim kurmaktan kaçınabilir, ancak bu durum paydaşların organizasyona karşı güvenini zedeleyebilir, organizasyonun şeffaf olmadığı izlenimini yaratabilir. Ancak, kriz zamanlarında, stratejik muğlaklığın iletişim taktiği olarak kullanılması, paydaşların organizasyona karşı olumsuz duygular geliştirmesini, güveninin azalmasını engelleyebilir. Güvenilir olan organizasyonlar da kendileri ile ilgili pozitif izlenimleri koruyabilir (Eisenberg, 1984). Birey düzeyinde de aynı durum geçerlidir. Williams ve Goss (1975) güvenilir bireyler için stratejik muğlaklı̆ıın iletişim taktiği olarak kullanımasını "karakterlerinin sigortası (character insurance)" olma fonksiyonu ile eşleştirmiştir. Güvenilirliği yüksek bireyler için açık ve net mesajlar risk içerir, çünkü her yeni bilgi alıcının negatif değerlendirmesi için potansiyel yaratır.

Stratejik muğlaklık "inkâr edilebilirlik" sağlayarak ayrıcalıklı pozisyonların korunmasına yardım eder. Örneğin, organizasyon, sektöründe lider bir konuma sahip ise, bu konumu zedelememe önceliği ile muğlak bir iletişim ile inkâr etme, suçu üstlenmeme yolunu kullanır. İletişim sürecinde belirsiz bir anlatım, üslup seçilmesi, görüşmeye gereksiz yere zarar verme potansiyeli olan belirli yorumlardan kaçmak için firsat sağlar (Eisenberg,1984; Millner, 2011; Sellnow ve Ulmer, 1995). Öte yandan, inkâr edebilirlik organizasyonu belirli bir faaliyete yönlendirmeden önce paydaşların tepkilerini fark etmeye yardımcı olur (Leitch ve Davenport, 2003). Muğlak bir iletişim sayesinde paydaşların neye en çok karşı olduklarını tespit ederek, organizasyon olarak nelerden ödün vermeleri gerektiğini, politikalarını, stratejilerini nasıl şekillendirmeleri gerektiğini belirleyebilir. Böylelikle organizasyon-paydaş arasındaki ilişki gereksiz yere zedelenmemiş olur.

Stratejik muğlaklık bir süreç gibi düşünülmelidir. Bir uçta en üst düzeyde açık ve net iletişim, diğer uçta en üst düzeyde muğlak iletişim bu sürekliliği yansıtır. Muğlaklık arttıkça da inkâr edebilirlik artar (Eisenberg, 1984, s.240). Alesina, Cukierman (1987) muğlaklık politikasını inceledikleri çalışmalarında da, kullanılan muğlaklığın derecelendirilebileceğini ifade ederek bu sürekliliğe vurgu yapmıştır.

Gelecek alternatifleri koruması: Eisenberg (1984), özellikle görev ile ilgili iletişimde stratejik muğlaklığın kullanımasının organizasyonun gelecekteki alternatif faaliyetlerini, planlarını koruduğunu, gelecek planlarından sapmalar için olanak yarattığını ifade etmiştir. Aragones ve Neeman (2000) seçim rekabetinde adayların kendilerini bilerek ve isteyerek belirsiz ve muğlak kelimeler ile ifade ettiklerini, böylelikle seçimleri kazandıklarında güvenilirliklerini zedelemeden istedikleri politikaları uygulama özgürlüğü elde ettiklerini ortaya koymuştur. Stratejik olan muğlak mesajlar, ne yapmayı planladığını açıkça söylemeden, gelecek alternatiflerini korumayı amaçlar (Tarbet, 2010). Ancak, organizasyon ya da birey düzeyinde gelecek planları açıça ifade edilip, planlar yerine getirilmediğinde, organizasyona ya da bireye karşı olumsuz bir algı ortaya çıkabilir.

Stratejik muğlaklık sağladığı bu fonksiyonların ötesinde bazı riskleri de getirebilir. Karar vericilerinin kontrolünün dışında çok sayıda yorum ve bakış açısının oluşması paydaşların direnç gösterme gücünü arttırabilir. Kontrol edilemeyecek sayıdaki görüş çeşitliliği paydaşlara kendilerini haklı görmeleri için bir neden yaratır ve birlikte hareket ederek, kendilerini ilgilendiren karara karşı çıkabilir- 
ler. Diğer bir risk, paydaşlar stratejik muğlaklığın tepkilerini kısıtlamak, kontrol etmek amacıyla kullanıldığını düşünebilir (Davenport ve Leitch, 2005). Organizasyonun kendi lehine olacak şekilde algıyı yönettiğini hissedebilirler ve bu durum organizasyona olan güveni olumsuz yönde etkileyebilir. Ya da, muğlak iletişim belirsizliği tetikleyerek bireylerdeki endişe ve kaygıyı artırır (Pulford ve Colman, 2007). Örneğin, Miller, Joseph ve Apker (2000) çalışanların, organizasyon içindeki rol tanımlarında muğlaklığın stratejik olarak kullanımına nasıl tepki verdiklerini analiz etmiş ve çalışanların stratejik muğlaklığa karşı duygusal, davranışsal ve iletişimsel boyutlarda tepkiler geliştirdiklerini ifade etmiştir.

Stratejik muğlaklığın organizasyon üzerinde yaratacağı diğer olumsuzluk ise, farklı yorumların farklı tepkiler ortaya çıkarması ve farklı tepkiler ile mücadele etmek zorunda kalan organizasyonda kaynak, zaman, maliyet açısından kayıplar yaşanmasıdır. Örneğin, ülkemizde kamu kurum ve kuruIuşlarında personel çalıştırılmasına dayalı hizmet alımı sözleşmeleri kapsamında çalıştırımakta olan işçilerin sürekli işçi kadrolarına veya mahalli idare şirketlerinde iş̧̧i statüsüne geçirilmesi ülke gündeminde uzun zamandır yer tutan bir konudur. Çok çeşitli ve dolayısıyla birbirleri ile çelişen çıkarlara sahip paydaşları ilgilendirmektedir. Konu ile ilgili yapılan açıklamalar bir taraftan bazı sorulara yanıt olurken, diğer taraftan yeni soruların ortaya çıkmasını tetiklemiş̧ir (sürecin ne zaman başlayacağı, hangi kriterlere göre taşeron işçilere kadro verileceği, hangi kamu kurumlarında çalışanların bu düzenlemeye dâhil edileceği, ne kadar süredir taşeron iş̧̧i olanların kapsama alınacağı, düzenlemenin kanun mu yoksa kanun hükmünde kararname ile kesinleştirileceği gibi). Düzenlemenin resmi gazetede yayınlanmasından sonra başvuru sürecine dair muğlaklıklar devam ettiği için kriterleri sağlamayan birçok kişinin başvurmasına neden olmuştur. Bu süreci yönetmek ile görevli olan kurumlar da kaynak, zaman, maliyet kayıpları ile karşılaşmıştır.

Kline, Simunich ve Weber (2009) stratejik muğlaklığın hangi koşullarda kullanılabileceğini açıklayan çalışmaların eksikliğini göz önünde bulundurarak stratejik muğlaklığın kullanılabileceği koşulları açıklamıştır. Krizin ilk dönemlerinde anlamlı bilgi bulunmadığında, yargıya intikal etmiş durumlar ile ilgili bilgi verirken, kişiye özel bilginin korunması gerektiğinde, kriz zamanlarında birbiri ile çelişen çıkarların yönetilmesi gerektiğinde stratejik muğlaklığın iletişim taktiği olarak kullanılabileceği ifade edilmiştir (Kline vd., 2009). Özellikle kriz zamanlarında kurum, devlet, paydaşlar ve/veya medya arasında çıkar çatışmasının olması muhtemeldir (Eisenberg, 1984). Nitekim kriz zamanları kullanılan muğlak bildirimler ile doludur (Millner, 2011). Belirsizliğin karmaşıklığın çok yoğun olduğu bir dönem olması, paydaşların bir açıklama beklemesi, organizasyonun en az zarar ile kriz dönemini atlatmak istemesi kriz zamanlarındaki muğlak mesajları tercih sebebi yapabilir. Tarbet (2010) kriz dönemindeki bankaların paydaşlar ile nasıl iletişim kurduğunu ve bu süreçte kullandığı muğlak mesaj örneklerini incelediği çalışmasında bankaların ayrıcalıkı konumlarını kaybetmemek adına muğlak mesajlar kullandığını göstermiştir.

\section{Kamu Sektöründe Bir Iletişim Taktiği Olarak Stratejik Muğlaklık}

Kamu sektöründe kamu problemlerine çözüm bulmak, sosyal fayda yaratmak, toplumsal düzeyde gelişmişliği sağlamak üzere çeşitli kamu politikaları, düzenlemeler, yönetmelikler düzenlenir. 


\section{Özlem ARACI}

Çünkü toplum kamu otoritelerinden sorunlara, taleplere, ihtiyaçlara cevap bulmasını bekler. Kamu otoriteleri de nasıl cevap vereceklerini bu süreçte paydaşlar ile nasıl iletişim kuracaklarını belirlemelidir. Kamu kurumları bir tarafta paydaşlarını bilgilendirme gerekliliği, diğer tarafta da birbirleri ile çelişen çıkarları olan paydaşlar arasında bir denge sağlama gerekliliği arasında iletişim stratejisini oluşturmaya çalışır. Stratejik muğlaklık bu iki gereklilik arasında iletişim için bir yol sağlar. Muğlak olmayı stratejik olarak kullanmak paydaşlar ile ilişkileri yönetmeyi kolaylaştırarak kamu kurumları için fayda yaratmaktadır (Davenport ve Leitch, 2005).

Kamu sektörü dinamikleri çerçevesinde stratejik muğlaklı̆ın değerlendirilmesinde ele alınacak ilk ikilem; bilgi edinme hakkı kanunu dolayısıyla bir tarafta yasal bir zorunluluk ile yüzleşen kamu kurumlarının diğer tarafta çelişen paydaş çıkarları arasında denge sağlama gerekliliğidir. Ülkemizde, yürürlüğe giren "Bilgi edinme hakkı" kanununa göre "Kurum ve kuruluşlar, bu kanunda yer alan istisnalar dışındaki her türlü bilgi veya belgeyi başvuranların yararlanmasına sunmak ve bilgi edinme başvurularını etkin, süratli ve doğru sonuçlandırmak üzere, gerekli idari ve teknik tedbirleri almakla yükümlüdürler (Bilgi Edinme Hakkı Kanunu, 2003: madde 5). Bilgi edinme hakkı kanunu dolayısıyla paydaşları bilgilendirmek üzere yasal zemin hazırlanmıştır. Kamu sektöründe faaliyet gösteren kurumlar diğer tüm faaliyetlerinde olduğu gibi yasalara uymak ile yükümlüdürler. Öte yandan, kamu kurumlarının yönetmek ve dikkate almak zorunda olduğu paydaşlarının, özel sektörde faaliyet gösteren birçok kurumun paydaşlarından daha fazla olması (Ring ve Perry, 1985), paydaş desteğini kaybetmemek için tüm paydaşları tatmin edecek ortak bir çözüm bulmakta zorlanmaları kamu kurumlarını farklı iletişim taktiklerine yönlendirmiştir.

Bu ikilem arasında kalan kamu kurumları için stratejik muğlaklığın görüş ve yorumları çeşitlendirme, değişimi kolaylaştırma, inkâr edebilirlik için alan sağlama, sektördeki ayrıcalıklı durumunu korumaya yardımcı olma, alternatif planlara geçişi kolaylaştırma fonksiyonları bir taraftan paydaşlar ile iletişim kurulmasını, diğer taraftan paydaş çıkarları arasında denge kurmayı sağlamış olacaktir.

Stratejik muğlaklık değerlendirilmesinde ortaya çıkan diğer ikilem, bir tarafta yönetimde açıklık, hesap verebilirlik, şeffaflık gibi ilkelerin kamu yöneticilerinin karar ve eylemlerinde gözetilen ilkeler olması, diğer taraftan kamu da gizlilik ilkesinin önemli bir politika aracı olmasıdır. Eleştirilerden kaçmak, kamunun kararları etkilemesini önlemek, çıkarları korumak amacı ile gizlilik ilkesi kamu yöneticilerinin kullandığı önemli bir politika aracıdır (Eryılmaz, 2016,s.399). Ancak demokratik düşüncenin gelişimi, modern kamu yönetimi sistemlerinin gelişmesi, kamu güveninin sağlanması gibi öncüller gizlilik karşısında açıkığın alanını artırmıştır. İlgili yazında ve uygulamada, yeni kamu yönetimi, yönetişim gibi kavramların yer bulması ile girişimci, katılımcı yönetim anlayışı ile birlikte şeffaflık, hesap verebilirlik kamu yönetimindeki yerini daha da güçlendirmiştir. Stratejik muğlaklığın bir iletişim taktiği olarak kullanılması organizasyonlara konu ile ilgili ayrıntılara yer vermeden, genel bilgilerin aktarılması için alan yaratır, böylelikle paydaşlar gizlilik ilkesi gereği bilgi edinme haklarından feragat etmemiş olurlar. Öte yandan, konu ile ilgili açıklamaların yapılmasıyla, paydaşlar tarafından kurumun hesap verebilirliğinin, şeffaflığının sorgulanmasının önüne geçilmiş olur. 
Yasalar, çelişen paydaş çıkarları, gizlilik, açıklık gibi ikilemler arasında kalan kamu kurumlarına yol açmak için stratejik muğlaklığın tercih edilmesinin daha farklı nedenleri de bulunmaktadır. Kamu kurumlarının politik bir çevrede faaliyet gösteriyor olması, kamu yöneticilerinin kaynakların sahibi değil, kaynakların yöneticisi olmaları, kamu hizmetlerinin etki alanının daha geniş olması paydaşlar ile ilişkileri önemli hale getirmektedir. Paydaşları kontrol etme isteği, paydaşlar ile işbirliği yaparak daha yaratıc sonuçlar elde etme isteği kurumların muğlak olmayı stratejik olarak tercih etmelerinin nedenlerindendir (Davenport ve Leitch, 2005). Paydaş görüşlerinin, yorumlarının çeşitlenmesini tetikleyen stratejik muğlaklık paydaşların katılımı için örtük bir katılımcılık sağlar. Böylelikle kurum hem kendi gücünü arttıracak hem de paydaşlarına tepkileri için bir alan yaratarak onları güçlendirmiş olacaktır (Davenport ve Leitch, 2005). Davenport ve Leitch (2005) kamu kurumu olarak faaliyet gösteren araştırma destekleme kurumlarını örneklem olarak seçtikleri çalışmada stratejik muğlaklığı, yetkinin paydaşlara delege edilmesi için bir yöntem olarak değerlendirmiş ve sistemin yeniden yapılanması sürecinde yaratıcı sonuçlar doğurduğu yönünde bulgular paylaşmıştir.

Kurumlar, etkilemeyi, kontrol etmeyi istedikleri paydaşlar ile ilişkilerini istedikleri yönde şekillendirmek için de muğlak iletişimi bir taktik olarak kullanabilir (Norman, 1992). Eğer açık ve doğrudan iletişim paydaşların kurum adına negatif yorumlarına neden olacak ise muğlak iletişim yolu ile ilişkiler şekillendirilir (Kline vd., 2009). Kamu kurumlarının hizmetleri dolayısıyla etki alanlarının geniş olması, kamu yöneticilerinin açık ve net iletişimi tercih edip, topluma verdikleri mesajdan uzaklaştıklarında toplum nezdinde tutarsız görünme, algılanma riski artacağı için de muğlaklık tercih edilebilir (Ring ve Perry, 1985). Muğlaklığın alternatif planlara geçişi kolaylaştırma fonksiyonu sayesinde kurum tutarsız görünmemiş ve buna bağlı olarak kamu güveni de zedelenmemiş olur.

Ring ve Perry $(1985$, s.279) kamu kurumlarının stratejilerini, politikalarını açık ve net şekilde açıklamamalarını iki gerekçe ile ifade etmiştir. İlki, açık ve net iletişimin politik olarak karşıtlık yaratma potansiyeli taşımasıdır (Ring ve Perry, 1985). Açık ve net olmak, başka hiçbir yoruma yer bırakmamak üzere sınır çizerek, dışındaki görüşleri, yorumları karşıt görüş ve yorumlar olarak gruplandırır. Oysaki muğlaklık, herhangi bir sınır çizmeden çok sayıda görüş ve yorumun ortaya çıkmasını destekleyerek kutuplaşma ortamı oluşturmaz. İkincisi ise stratejilerin, politikaların açık ve net bir şekilde ifade edilmesi yürütücülerin takdir yetkilerinin azaldığına inanarak, konuya yeterince önem vermemeleri riskini taşımasıdır (Ring ve Perry, 1985). Açık ve net politikalar, yürütücülere tam olarak neyi, nasıl yapmaları gerektiğini açıklayarak yürütücülerin yorum ve takdir alanlarını kısıtlamaktadır. Süreçteki katılımı kısıtlanan yürütücü konuya gerekli önemi vermeyebilir. Vereceği kararda sorumluluğu olmadığını bilmek, yürütücünün konuya karşı geliştireceği özeni azaltabilir.

Stratejik muğlaklığı bir iletişim taktiği olarak kamu sektöründe faaliyet gösteren kurumlar için önemli kılan nedenlerden biri oluşacak yorumları, görüşleri yönetme olanağı vermiş olmasıdır. Kamu kurumlarının etki alanının özel sektör kurumlarının etki alanından daha geniş olması dolayısıyla, kuruma ilişkin negatif algı yaratacak, karşıtlık oluşturacak açık mesajların olumsuz etkisi daha fazla hissedilecektir. Oysaki stratejik muğlaklık sayesinde kamu kurumları bu geniş etki alanında oluşacak yorumları, görüşleri yönetme olanağına kavuşmuş olacaktır. Diğer nedeni ise, stratejik 
Özlem ARACI

muğlaklık paydaşların konu ile ilgili görüşleri, yorumları ile katılımlarını destekler. Kurumların dikkate alması gereken, paydaşları ne kadar çeşitlilik gösteriyorsa, o kadar farklı görüşün ve yorumun ortaya çıkmasını sağlayıp stratejik muğlaklı̆ın yarattığı faydayı artırmak olmalıdır (Leitch ve Davenport, 2003). Kamu kurumlarının vatandaşların denetimine, tetkikine tabi olması stratejik muğlaklığın önemini artıran diğer önemli bir nedendir (Eisenberg, 1984). Açık bir iletişim yerine muğlak bir iletişim, vatandaşların farklı farklı görüşlere sahip olmasını sağlar, bu da konu ile ilgili kamunun desteğini almak için bir yol sağlar.

\subsection{Kamu Sektöründe Bir Illetişim Taktiği Olarak Stratejik Muğlaklık ve Etik}

Etik kavramı, iyi-kötü, doğru-yanlış değerlendirmelerini yapmaya yarayan değerler, ilkeler ve kurallar ile tanımlanabilir (Eryılmaz, 2016, s.403).Ne yapılması gerektiğini belirleyen değerler, ilkeler ve kurallar olarak da tanımlanabilir. Etik kavramını önemli hale getiren, karar ya da davranışların sadece bireyin kendisini değil, diğerlerini de etkiliyor olmasıdır.

Kamu sektöründe faaliyet gösteren kurumların karar ya da davranışlarından etkilenecek alanının genişliği göz önünde bulundurulduğunda etik konusu kamu sektörü için daha önemli hale gelmektedir. Kamu güveni oluşturma, kamu güvenini sürdürme endişesi kamu sektöründeki etik konusunu özel sektörden farklılaştırmaktadır. Kamuoyu, toplum çıkarlarının korunduğu, görev ve kaynakların bireysel çıkarlar uğruna suiistimal edilmediği konusunda kamu kurumlarına güven duymak ister (Eryılmaz, 2016). Etik ilkelere uygun davranan kamu kurumları bu güveni sağlar. Etik konusunu kamu sektöründe faaliyet gösteren kurumlar için daha önemli kılan nedenlerden biri de; hukukun üstünlüğü ilkesidir. Hiç kimse bireysel çıkarlar uğruna, kendi itibarını yükseltme uğruna kendini hukuktan üstün göremez. Diğer bir neden ise; tüm bireylerin eşitliği ilkesidir. Etik dışı uygulamalar ile birey kendisini diğerlerinden daha üstün tutmamalıdır (Shafritz, Russell, Borick ve Hyde, 2016).

Kamu yönetimi, devletin yürütme gücü olarak, kaynakları devletin amaçlarını gerçekleştirmek üzere etkin ve verimli şekilde kullanarak kamu yararı oluşturmaya çalışır. Gözetilmesi gereken kamu yararı yasalar, yönetmelikler, genelgeler, yönetmelikler ile korunur. Kamu görevlileri de faaliyetlerinde sadece yasal sorumluklarının değil, etik sorumluluklarının da bilincinde olmalıdır.

Çeşitli meslek dallarında etik davranma sorumluluğu ilkeler, değerler etik kodlar olarak resmileştirilmekte, etik ilkelere aykırılık söz konusu olduğunda resmi yaptırımlar ile müdahale edilebilmektedir. Ülkemizde kamu yönetiminde uygulanmak üzere 2005 yılında "Kamu Görevlileri Etik Davranış İlkeleri ile Başvuru Usul ve Esasları Hakkında" yönetmelik yayınlanmıştır. Bu yönetmelik, kamu görevlilerin görevlerini yerine getirirken etik ilkelerin farkında olmalarını, toplumun kamu görevlilerinden beklemeye hakkı olduğu davranışlar konusunda bilgilendirilmesini, toplumda güvensizlik yaratmadan halkın kamu yönetimine güvenini artırmayı amaçlamaktadır (Kamu Görevlileri Etik Davranış İlkeleri ile Başvuru Usul ve Esasları Hakkında Yönetmelik, 2005). 
Görevin yerine getirilmesinde kamu hizmeti bilinci, halka hizmet bilinci, hizmet standartlarına uyma, amaç ve misyona bağlılık, dürüstlük ve tarafsızlık, saygınlık ve güven, nezaket ve saygı, yetkili makamlara bildirim, çıkar çatışmasından kaçınma, görev ve yetkilerin menfaat sağlamak amacıyla kullanımaması, hediye alma ve menfaat sağlama yasağı, kamu malları ve kaynaklarının kullanımı, savurganlıktan kaçınma, bağlayıcı açıklamalar ve gerçek dışı beyan, bilgi verme, saydamlık ve katılımcılık, yöneticilerin hesap verme sorumluluğu, eski kamu görevlileri ile ilişkiler, mal bildiriminde bulunma olmak üzere kamu sektöründe geçerli olan etik ilkeler belirlenmiştir (Kamu Görevlileri Etik Davranış İlkeleri ile Başvuru Usul ve Esasları Hakkında Yönetmelik, 2005).

Kamu görevlileri kamu yararını gözeterek karar verme zorluğu yaşasa da bundan daha zor olanı etik kararlar vermektir (Bowman, 1991). Mesleki düzeyde, organizasyon düzeyinde etik ilkeler ve değerler resmileştirilerek etik kodlar haline getirilse de, uygulanması bireylerin içsel kontrolü ve kişisel sorumluluğu ile yakından ilgilidir (Martinez, 2009; Rosenbloom, 1998). Cooper vd., (1998) kamu görevlileri için yasaların dışsal bir denetim unsuru, etik değerlerin ise içsel bir denetim unsuru olduğunu ifade etmiştir.

Stratejik muğlaklığın kamu sektöründe bir iletişim taktiği olarak yarattığı avantajlardan sonra etik olup olmadığının da sorgulanması gerekmektedir. Kamu yararını, kamu güvenini zedeleyecek bir amaç olarak kullanılması etik endişeleri artıracaktır. Kurumlar paydaşları ile iletişimde müphem bir iletişim yolu tercih edilebileceği gibi, açık, şüpheye yer vermeyecek bir iletişim yolu da tercih edilebilir. Söz konusu kamu sektöründe faaliyet gösteren kurumlar olduğunda, kararları ve uygulamaları ile çok çeşitli kesimleri ilgilendiren geniş bir etki alanına sahip oldukları için, hesap verebilirlik, şeffaflık ilkelerine önem verildiği için, kamu güveninin sağlanması endişesi olduğu için davranışın etik olup olmadığı daha da önem kazanmaktadır.

Stratejik muğlaklığı etik anlayış ile karşı karşıya getiren neden, stratejik muğlaklığın inkâr etmek, sorumluluktan kaçmak için bir alan yaratmasıdır (Paul ve Strbiak, 1997). İnkâr edilebilirlik her ne kadar kurum ile paydaşlar arasındaki ilişkileri gereksiz yere zedelememek uğruna kullanılan muğlak bir iletişimin sonucu olsa da etik endişeler yaratmaktadır. Paul ve Strbiak (1997) çalışmasında ifade edildiği üzere, stratejik muğlaklığın etik ile çelişen yönleri onun faydasını kısıtlamaktadır. İyi-kötü, doğru- yanlış değerlendirmesini yapmaya yarayan ilkelerin, değerlerin muğlaklığın sağladığı gelecek alternatif planların korunması, kurumun ayrıcalıklı pozisyonunun korunması, organizasyon düzeyinde değişimin kolaylaştıııması, farklı görüşlerin ortaya çıkışının desteklenmesi gibi faydalar ile çelişmesi etik sorgulamanın yapılmasını gerektirir. Örneğin, kurumlar, muğlaklığı bilinçli şekilde tüm paydaşları sürece dâhil etmek, onların yorumlamaları neticesinde kararlarını şekillendirmek amacı ile kullanıyor olabilir. Ama bilgiyi manipüle etmek, kurumun yanlışlarını örtmek amacıyla kullanıyorsa etik bir kullanım olduğu söylenemez (Millner, 2011). Stratejik muğlaklığın etik endişeleri artırmasının diğer bir nedeni, kurumların tüm bilgiyi ayrıntılarıyla değil sadece yeterli olduğu kadarı ile paydaşlarına aktarmasıdır (Tarbet, 2010, s.14), kurumlar gizli detayları korurken, durum hakkında çok genel bilgiler verirler (Leitch ve Davenport, 2003). Kurumun tüm bilgiyi paylaşmamak için geçerli nedeni olabilir ancak bu noktada sorgulanması gereken elde tutulan, paylaşılmayan bilginin paydaşlara yarar mı yoksa zarar mı getireceğidir (Tarbet, 2010). 
Stratejik muğlaklığın hangi durumlarda etik, hangi durumlarda etik dışı olduğuna dair ortaya çıkan görüşlere baktığımızda hem fikir olunan bir görüş olmadığı ortaya çıkmaktadır. Tarbet (2010) çalışmasına göre, elde tutulan, paydaşlara aktarılmayan bilgi, onları herhangi bir zarar ya da risk altında bırakmıyorsa, bir iletişim taktiği olarak stratejik muğlaklık kullanılabilir. Ancak elde tutulan, aktarılmayan bilgi paydaşlara zarar verecek ya da paydaşların negatif tepkilerine yol açacak bir durum yaratıyorsa, muğlaklığın bir iletişim taktiği olarak kullanılması etik olmayacaktır (Tarbet, 2010). Paul ve Strbiak (1997) stratejik muğlaklığın etik bir iletişim taktiği olup olmadığının, stratejik muğlaklığı kullanan kişiye göre değişeceğini ifade etmektedir. Kişi, iletişim sürecinde, bilinçli bir şekilde etik olmayan amaçlar ile stratejik muğlaklığı tercih ettiğinde etiğin önemini azaltmış olur. Ancak mantıksal olarak etik davranma endişesi olan bir kişi tarafından kullanıldığında stratejik muğlaklık etik bir iletişim alternatifidir (Paul ve Strbiak, 1997). Ulmer ve Sellnow (2000) ise paydaşlara eksiksiz ve tarafsız bilgi iletildiğinde muğlaklığın etik olabileceğini ifade etmektedir. Ancak stratejik muğlaklık yorumlamayı, anlamlandırmayı güçleştirecek şekilde eksik ve taraflı bilgi iletiyorsa, etik olmayacaktır (Ulmer ve Sellnow, 1997). Kline vd., (2008) kriz zamanlarında ve tüm gerçeklerin bilinmediği durumlarda stratejik muğlaklığın bir iletişim taktiği olarak kullanılmasının etik dışı olmadığını ifade etmişlerdir. Çünkü gerçekler ortaya çıtığında, kurumdan paydaşlarına doğru yeterli bilginin aktarılacağı beklentisi vardır.

Kamu görevlileri bir taraftan anayasaya, yasalara uygun hareket ederken diğer taraftan toplumun değerleri ile uyumlu, mesleki standartlara uygun, vatandaş çıkarlarını koruyan bir tutum sergilemelidirler (Eryılmaz, 2016). Bir iletişim taktiği olarak stratejik muğlaklığı, "Kamu Görevlileri Etik Davranış illkeleri ile Başvuru Usul ve Esasları Hakkında” başlıklı yönetmelikte belirlenen "ilgili etik ilkelere" göre değerlendirdiğimizde;

Görevin yerine getirilmesinde kamu hizmeti bilinci ilkesine göre "Kamu görevlileri, kamu hizmetlerinin yerine getirilmesinde; sürekli gelişimi, katılımcılığı, saydamlığı, tarafsızlığı, dürüstlüğü, kamu yararını gözetmeyi, hesap verebilirliği, öngörülebilirliği, hizmette yerindenliği ve beyana güveni esas alırlar" (Kamu Görevlileri Etik Davranış İlkeleri ile Başvuru Usul ve Esasları Hakkında Yönetmelik, 2005: madde 5).

Kamu görevlilerinin saydam, dürüst, hesap verebilir olma gerekliliği iletişim taktiği olarak stratejik muğlaklık ve etik arasındaki çelişkiyi artırabilir. Nihayetinde, stratejik muğlaklık tanımı gereği farklı çıkarlar arasında denge kurma amacı ile daha soyut bir dil ile, konu ile ilgili detaylara yer vermeksizin, sonrasında konuşmacıyı bağlayıcı açıklamaları kapsamayacak mesajları içerir. Oysaki kamu yetkisi ve kaynağı kullanmak hesap verebilir olmayı gerektirir. Hesap verebilirlik, "bir kişinin veya kurumun eylem ve işlemleri konusunda ilgililerin sorgularına muhatap olması, eleştirilerine açık olması, cevap vermesi, haklılı̆ını ortaya koyması ve sonucuna katlanması" şeklinde tanımlanabilir (Eryılmaz, 2016, s.7). Hesap verebilirliğin unsurlarından biri "hesap soranın hesap verecek olanların yerine getirdiği davranışları ve verdiği bilgileri sorgulayabilme kanallarının bulunmasıdır (Eryılmaz, 2016, s.371). Hesap verebilirlik hesap verenin istediği nitelikte ve nicelikte bilgiyi değil, hesap soranın istediği nitelikte ve nicelikte bilgiyi sağlıyor olmayı gerektirir. Stratejik muğlaklık ter- 
cih edildiğinde ise, çok fazla ayrıntı içermeyen genel bilgiler ya da çeşitli şekilde yorumlanabilecek müphem mesajlar kullanılır, hesap vermek zorunda bırakacak mesaj içerikleri tercih edilmez. Etik ilkelere uygun davranmak bireyin içsel kontrolü ve kişisel sorumluluğu ile ilişkili olduğundan (Martinez, 2009; Rosenbloom, 1998), dürüstlük, hesap verebilirlik gibi kamu hizmetinde aranan etik ilkelerin bilincine sahip bireyler tarafından stratejik muğlaklık kullanıldığında etiğin önemi azaltılmamış olur.

Hizmet standartlarına uyma ilkesine göre "Kamu kurum ve kuruluşlarının yöneticileri ve diğer personeli kamu hizmetlerini belirlenen standartlara ve süreçlere uygun şekilde yürütürler, hizmetten yararlananlara iş ve işlemlerle ilgili gerekli açıklayıcı bilgileri vererek onları hizmet süreci boyunca aydınlatırlar" (Kamu Görevlileri Etik Davranış Illkeleri ile Başvuru Usul ve Esasları Hakkında Yönetmelik, 2005: madde 7).

Kamu ile iletişim sürecinde bilgiler paylaşılırken özellikle aldıkları hizmet ile ilgili bilgi verilememesi paydaşların durumu sorgulamalarına, kuruma karşı güvensizlik oluşmasına neden olabilir. iletişim taktiği olarak stratejik muğlaklık tercih edildiğinde, paydaşlara eksiksiz ve tarafsı bilgi iletildiğinde etik endişeler yaratılmamış olur. Kamu otoritelerinin kamu güveninin zarar görmemesi için paydaşlar ile paylaşılmayacak bilginin paydaşların çıkarlarını zedeleyecek bilgi olmadı̆̆ından emin olması gerekmektedir. Aksi halde stratejik muğlaklığın bir iletişim taktiği olarak bilerek ve isteyerek kullanılması etik olarak değerlendirilmeyebilir.

Dürüstlük ve tarafsızlık ilkesine göre "Kamu görevlileri tüm eylem ve işlemlerinde yasallık, adalet, eşitlik ve dürüstlük ilkeleri doğrultusunda hareket ederler, görevlerini yerine getirirken ve hizmetlerden yararlandırmada dil, din, felsefi inanç, siyasi düşünce, ırk, cinsiyet ve benzeri sebeplerle ayrım yapamazlar, insan hak ve özgürlüklerine aykırı veya kısıtlayıcı muamelede ve fırsat eşitliğini engelleyici davranış ve uygulamalarda bulunamazlar"(Kamu Görevlileri Etik Davranış ilkeleri ile Başvuru Usul ve Esasları Hakkında Yönetmelik, 2005: madde 9).

Kamu hizmetleri ayrım gözetilmeksizin vatandaşlara sunulur. Kamu görevlileri görevlerini yerine getirirken sadece yasalara uygunluktan değil, tarafsızlık, adalet, eşitlik ilkelerinin yerine getirilmesinden sorumludur. İletişim taktiği olarak stratejik muğlaklık kullanıldığında verilen mesajlar da bir paydaşın çıkarlarını diğer paydaşların çıkarlarından daha üstün tutacak içerikler kullanılmadığında, içeriğe dahil edilen bilgi tarafsız olarak ve ayrım gözetilmeksizin tüm kesimlere duyurulduğunda etik anlayışın “dürüstlük ve tarafsızlık ilkesi” ile muğlaklık arasındaki çelişki azalabilir.

Bağlayıcı açıklamalar ve gerçek dışı beyan ilkesine göre "Kamu görevlileri, görevlerini yerine getirirken yetkilerini aşarak çalıştıkları kurumlarını bağlayıcı açıklama, taahhüt, vaat veya girişimlerde bulunamazlar, aldatıı ve gerçek dışı beyanat veremezler" (Kamu Görevlileri Etik Davranış Illkeleri ile Başvuru Usul ve Esasları Hakkında Yönetmelik, 2005: madde 18).

Bu noktada iletişim taktiği olarak stratejik muğlaklık kullanıldığında, kamu otoritelerinin açıklamalarında gerçeği farklı yansıtmaktan kaçınarak, paydaşların konu ile ilgili farklı görüşler, yorumlar üretmesini tetiklemek amaçlanmalıdır. Stratejik muğlaklığın faydasını ortaya çıkaran da görüş ve yorum çeşitliliğin oluşmasıdır. Farklı görüşler, yorumlar bir nevi kamuoyu yoklaması gibi tepkilerin 
Özlem ARACI

öngörülebilirliğine katkıda bulunur. Paydaşlara eksiksiz ve tarafsı bilgi aktarıldığında stratejik muğlaklığın etik olabileceği görüşüne dayanarak (Ulmer ve Sellnow, 1997), kamu kurumlarının paydaşları ile iletişiminde stratejik muğlaklığı kullanması ve "bağlayıcı açıklamalar ve gerçek dış beyan ilkesi" arasındaki çelişkiyi azaltabilir.

Bilgi verme, saydamlık ve katılımalık ilkesine göre "Kamu görevlileri, halkın bilgi edinme hakkını kullanmasına yardımcı olurlar. Gerçek ve tüzel kişilerin talep etmesi halinde istenen bilgi veya belgeleri, 4982 sayılı Bilgi Edinme Hakkı Kanununda belirlenen istisnalar dışında, usulüne uygun olarak verirler" (Kamu Görevlileri Etik Davranış IIlkeleri ile Başvuru Usul ve Esasları Hakkında Yönetmelik, 2005: madde 19).

Vatandaş, bilgi edinme hakkının bilinci ile doğrudan ya da dolaylı olarak kendisini etkileyecek olan kararlar konusunda açık ve şeffaf olunmasını bekler. Kriz zamanları gibi tüm gerçeklerin bilinmediği durumlarda vatandaşın açık ve şeffaf iletişim beklentisi ile gerçekleşen arasındaki fark açılabilir. Beklenen ve gerçekleşen arasındaki bu fark kamu kurumlarına duyulan güveni olumsuz etkiler. Etik ilkelerin bilinci ile stratejik muğlaklığın kullanımı ise hiç iletişim kurmamak yerine müphem mesajlar ile kamuyu bilgilendirmeye ve güvenini korumaya yardımcı olabilir.

Katılımclık ile ilgili olarak "Kamu görevlileri, kamu hizmetleri ile ilgili temel kararların hazırlanması, olgunlaştırılması, alınması ve bu kararların uygulanması aşamalarından birine, bir kaçına veya tamamına, aksine yasal bir hüküm olmadıkça, o karardan doğrudan ya da dolaylı olarak etkilenecek olanların katkıda bulunmasını sağlamaya dikkat ederler" (Kamu Görevlileri Etik Davranış Ilkeleri ile Başvuru Usul ve Esasları Hakkında Yönetmelik, 2005: madde 19).

Kamu hizmetlerinin yerine getirilmesinde katılımcılığın sağlanması hususunda stratejik muğlaklığın iletişim taktiği olarak kullanılması paydaşların çeşitli yorumları ve görüş açılarını sunmaları için ortam yaratarak sürece katılımlarını destekler. Katılımclık bir taraftan paydaşlar üzerinde görüşlerine değer verildiği algısı yaratırken, diğer taraftan hangi görüşlerin, uygulamaların paydaşlar tarafından olumlu ya da olumsuz tepki ile karşılanacağı noktasında karar vericilere öngörü sağlar. Stratejik muğlaklık, etik anlayışın "katılımclık ilkesini” destekleyerek paydaşların kamu kurumlarının karar ve uygulamaları üzerindeki etkisini artırabilir.

\section{Sonuç ve Öneriler}

Organizasyonların öncelikli görevlerinden biri çevreleri ile ilişkilerini yönetmektir. Gerek organizasyon içi iletişimde, gerekse organizasyon dışı iletişimde uygulanmak üzere seçilen strateji organizasyonun çevresi ile ilişkisinin yönetiminde etkin bir role sahiptir. Organizasyonun kararlarından, uygulamalarından doğrudan ya da dolaylı olarak etkilenen ya da organizasyonu etkileyen paydaşların davranışlarının etkilenmesi, motivasyonunun sağlanması, ikna edilmesi etkin bir iletişim stratejisi ile mümkün olacak ve organizasyonun amaçlarının gerçekleştirilmesine katkı sağlayacaktır.

Bu çalışmada, organizasyonlara iletişim stratejisinin seçiminde bugüne kadar etkin iletişimin yolu olarak tarif edilen açık ve net iletişime alternatif olarak stratejik muğlaklık kamu sektörü dina- 
mikleri çerçevesinde incelenmiştir. Kamu sektörü dinamikleri çerçevesinde stratejik muğlaklığın değerlendirilmesini anlamlı kılan, çok çeşitli paydaşlara sahip kamu kurumlarının birbirleri ile çelişen paydaş çıkarları arasında denge kurması gerekliliğini kamu hizmet bilinci, şeffafık, hesap verebilirlik, tarafsızık, kamu güveninin kazanılması gibi değerler ve ilkeler ışığında gerçekleştirmeye çalışmalarıdır. İletişim taktiği olarak stratejik muğlaklık, kamu sektöründe faaliyet gösteren kurumların belirlenen değerlerden, ilkelerden kopmadan denge kurmasına yardımcı olmaktadır. Ancak, stratejik muğlaklığın bir iletişim taktiği olarak kullanılması etik davranma bilincinin önemini artırmaktadır. Aksi halde, kurumların kendileri ile ilgili bilgileri manipüle etme, paydaş çıkarlarına zarar verecek şekilde bilginin saklanması, kamu güvenini suiistimal etme amacı ile kullanılması stratejik muğlaklığı etik olmaktan uzaklaştıracaktır.

İletişim taktiği olarak stratejik muğlaklı̆ın farklı görüşlere ve yorumların oluşmasına olanak sağlayarak iletişim sürecinde yaratıcılı̆̆ı tetiklemesi, paydaşların farklı görüşleri ile sürece katılımlarının sağlanması, paydaşlardan gelecek tepkilere göre kararı ya da uygulamayı düzeltme, gözden geçirme olanağı sağlaması, birbirinden farklı ve çelişen çıkarlar arasında denge kurmayı sağlaması, organizasyonun paydaşların gözünde tutarsız duruma düşmesini engellemesi, paydaşların görüş ve yorumlarını organizasyonun amaç ve stratejilerine yaklaştırarak değişimi kolaylaştırması gibi faydaları açık ve net iletişim taktiği karşısında stratejik muğlaklığı güçlendirmektedir. Eisenberg (1984) iletişimde açık olmak yerine muğlaklığın stratejik olarak kullanımını amaçların gerçekleştirilmesinde daha etkin bir iletişim pratiği olarak değerlendirmiştir.

Stratejik muğlaklığın etkin bir iletişim pratiği olmasını etkileyen öncüller gelecek çalışmalar için potansiyel bir araştırma sorusu olabilir. Örneğin, farklı kültürler iletişim taktiği olarak stratejik muğlaklığa farklı tepkiler geliştirebilir. Kültürlerin belirsizlikten kaçınma boyutuna göre farklılaşmaları, bireylerin stratejik muğlaklığa karşı geliştirecekleri tepkileri etkileyebilir. Stratejik muğlaklık ve belirsizliğe karşı geliştirilen tolerans arasında ilişki olabilir. Organizasyon ve paydaşları arasındaki güven düzeyi de stratejik muğlaklığın etkin bir iletişim pratiği olması üzerinde etkili olabilir. Organizasyon ve paydaşları arasındaki güven düzeyi azaldıkça, paydaşlar stratejik muğlaklığın kendi çıkarlarını zedeleme amacı ile kullanıldığını düşünebilir, dolayısıyla etkin bir iletişim taktiği olmaktan uzaklaşabilir.

Stratejik muğlaklığın etkinliği üzerinde etkili olan öncüller dışında stratejik muğlaklık kamu sektörü ve özel sektör dinamikleri çerçevesinde karşılaştırmalı olarak incelenebilir. Özel sektörde faaliyet gösteren kurumlar ile paydaşları arasındaki ilişkinin farklılı̆ı, paydaş çeşitliliğinin kamu sektöründe faaliyet gösteren kurumlara görece kısıtlı olması karşılaştırmayı anlamlı kılabilir. Stratejik muğlaklık ile ilgili bir diğer potansiyel araştırma konusu ölçümü ile ilgilidir. Eisenberg (1984) çalışmasında muğlaklığın ölçülmesi için dikkate alınması gereken üç önemli faktör; iletişim hedefleri, iletişimde kullanılan kelime tercihleri, alıının yorumu olarak sıralanmıştır. Müphem bir mesajın kaç farklı şekilde yorumlandığı, ne derece karmaşık bulunduğu, mesajı anlamlandırmanın zorluğu muğlaklığın ölçümündeki olası göstergeler olabilir. 
Özlem ARACI

\section{Kaynaklar}

Alesina, A., Cukierman, A. (1987).The Politics of Ambiguity.NBER Working Paper Series.Cambirdge, MA.

Aragones, E., \& Neeman, Z. (2000). Strategic Ambiguity in Electoral Competition. Journal of Theoretical Politics, 12(2), 183-204.

Bilgi Edinme Hakkı Kanunu (2003). T.C.Resmi Gazete, 25269, 24 Ekim 2003.

Bowman, J. (1991). Introduction:Ethical theory and practice in public management. J. Bowman içinde, Ethical frontiers in public management: Seeking new strategies for resolving ethical dilemmas. San Francisco: Jossey Bass.

Cheney, G., \& Christensen, L. (2001). Organizational Identity: Linkages between internal and external communication. F. Jablin, \& L. Putnam içinde, Then New Handbook of Organizational Commmunication: Advances in Theory, Research and Methods (s. 231-269). London: Sage .

Contractor, N., \& Ehrlich, M. (1993). Strategic ambiguity in the birth of a loosely coupled organization: The case of a $\$ 50-$ million experiment. Management Communication, 6(3), 251281.

Cooper , P., Brady, L., Hardeman, O., Hyde , A., Naff, K., Ott, J., \& White, H. (1998). Public Administration for the Twenty First Century. Fort Worth: Harcourt Brace College Publishers.

Daft, R. (2010). New Era of Management. South Western: Cengage Learning.

Davenport, S., \& Leitch, S. (2005). Circuits of Power in Practice: Strategic Ambiguity as Delegation of Authority. Organization Studies, 26(11), 1603-1623.

Donaldson, T., \& Preston, L. (1995). The stakeholder theory of the corporation: Concepts, evidence and implications. Academiy of Management Review, 20(1), 65-91.

Eisenberg, E. (1984). Ambiguity as Strategy in Organizational Communication. Communication Monographs, 51, 227-242.

Eisenberg, E., \& Goodall, H. (1997). Organizational Communication: Balancing Creativity and Constraint. New York: St Martin's Press.

Eryılmaz, B. (2016). Kamu Yönetimi: Düşünceler, Yapılar,Fonksiyonlar, Politikalar (9.Baskı b.). Kocaeli: Umuttepe Yayınları.

Goodall, B., Trethewey, A., \& McDonald, K. (2006). Strategic Ambiguity, Communication and Public Diplomacy in an Uncertain World: Principles and Practices. Consortium for Strategic Communication (s. 1-14). Arizona State University. 
Kline, S., Simunich, B., \& Weber, H. (2008). Understanding the effects of nonstraight forward communication in organizational discourse: The case of equivocal messages and corporate identity. Communication Research, 35(6), 770-791.

Kline, S., Simunich, B., \& Weber, H. (2009). The use of equivocal messages in responding to corporate challenges. Journal of Applied Communication Research, 37(1), 40-58.

Leitch, S., \& Davenport, S. (2003). Strategic Ambiguity in Communicating Public Sector Change. Journal of Communication Management, 7(2), 129-139.

Leitch, S., \& Davenport, S. (2007). Strategic Ambiguity as a Discourse Practice: The Role of Keywords in the Discourse on Sustainable Biotechnology. Discourse Studies, 9(1), 43-61.

Markham, A.(1996). Designing discourse: A critical analysis of strategic ambiguity and workplace kontrol.Management Communication Quarterly,9(4),389-421.

Martinez, J. (2009). Public Administration Ethics for the 21st Century. California: ABC-CLIO LLC.

Miller, K., Joseph, L., \& Apker, J. (2000). Strategic ambiguity in the role development process. Journal of Applied Communication Research, 28(3), 193-214.

Millner, A. (2011). Strategic Ambiguity and Proxy Communication in Orgnizational Crises:The Peanut Corporation of America Case. University of Kentucky: Proquest LLC.

Norman, F. (1992). Discourse and Social Change. Cambridge: Polity.

Paul, J., \& Strbiak, C. (1997). The Ethics of Strategic Ambiguity. Journal of Business Communication, 34(2), 149-159.

Pulford, B., \& Colman, A. (2007). Ambiguous games: Evidence for strategic ambiguity aversion. The Quarterly Journal of Experimental Psychology, 60(8), 1083-1100.

Putnam, L. (1981). Equivocal Messages in Organizations. Annual Meeting of the International Communication Association (s. 1-46). Minneapolis: Educational Resources Information Center.

Ring, P., \& Perry, J. (1985). Strategic Management in Public and Private Organizations: Implications of Distincitve Contexts and Constraints. Academy of Management Review, 10, 276-286.

Rosenbloom, D. (1998). Public Administration. New York: McGraw-Hill.

Samovar, L. (1962). Ambiguity and unequivocation in the Kennedy-Nixon televesion debates. Quarterly Journal of Speech, 48, 277-279.

Sellnow, T.L.\& Ulmer, R.R.(1995). Ambiguous argument as advocacy in organizational crisis communication. Argumentation and Advocacy, 31, 138-150.

Shafritz, J., Russell, E., Borick, C., \& Hyde, A. (2016). Introducing Public Administration (9th edition b.). New York: Routledge. 
Smith, S., Atkin, C., \& Roznowski, J. (2006). Are "drink responsibly" alcohol campaigns strategically ambiguous? Health Communication, 20(1), 1-11.

Tarbet, S. (2010). Communicating During an Economic Crisis: An Examination of the Use of Strategic Ambiguity Within the Banking Industry. Clemson University: UMI,Proquest Dissertations.

Ulmer, R., \& Sellnow, T. (1997). Strategic Ambiguity and the Ethic of Significant Choice in the Tobacco Industry's Crisis Communication. Communication Studies, 48(3), 215-233.

Ulmer, R., \& Sellnow, T. (2000). Consistent Questions of Ambiguity in Organizational Crisis Communication: Jack in the Box as a Case Study. Journal of Business Ethics, 25(2), 143-155.

Ulmer, R.R., Sellnow, T.L.. \& Seeger, M.W. (2011). Effective crisis communication:Moving from crisis to opportunity (2nd ed.). Los Angeles, CA: Sage Publications, Inc.

Weick,K.E. (1995).Sensemaking in organizations. Thousand Oaks,CA:Sage

Williams, M., \& Goss, B. (1975). Equivocation: Character Insurance. Human Communication Research, 1, 265-270.

Zimbardo, P. (1960). Verbal ambiguity and judgemental distortion. Psychological Reports, 6, 5758. 